\title{
Cyanobacteria: health and research possibilities
}

\author{
Daniel A. Belshaw ${ }^{\mathrm{A}, \mathrm{C}}$, Michelle C. Moffitt ${ }^{\mathrm{B}}$ \\ and George Truman ${ }^{\mathrm{C}}$ \\ ${ }^{\mathrm{A}}$ NSW Public Health Officer Training Program, \\ NSW Ministry of Health \\ ${ }^{\mathrm{B}}$ School of Biomedical and Health Science, \\ The University of Western Sydney \\ ${ }^{\mathrm{C}}$ Public Health Unit, Nepean Blue Mountains \\ Local Health District
}

Cyanobacteria are a subset of prokaryotic bacteria (also known as blue-green algae) possessing a cell wall and chlorophyll A, contributing about $35 \%$ of global photosynthesis. Cyanobacteria are found on all continents in soils and fresh, brackish and salt water, living independently or in symbiosis. ${ }^{1}$ As cyanobacteria are found in all water bodies, they have the potential to affect the quality of drinking and recreational water and pose a potential health risk to the public.

Cyanobacteria can produce blooms under particular environmental conditions (e.g. nutrient run off, low or no water flow, low or minimal wind, and consistent warm temperatures). ${ }^{2}$ Blooms decrease oxygenation of water, which can suffocate fish, and can produce cyanotoxins that can lead to animal and human sickness or death.

Cyanotoxins are secondary metabolic products. Various cyanobacteria can produce cyanotoxins that may be hepatotoxic or neurotoxic. ${ }^{1}$ Other molecules may affect the colour, taste and smell of water. Humans can ingest cyanotoxins when drinking contaminated water or through recreational water use. Symptoms in humans include gastroenteritis, skin irritation, ear and eye irritation, fever and in severe cases, weakness, staggering, muscle twitching and gasping. 1,2

In New South Wales, the three most common species of cyanobacteria, Microcystis auruginosa; Anabaena circinalis and Cylindrospermopsis raciborskii, can all produce cyanotoxins. ${ }^{1}$

Microcystins are produced by the cyanobacterial genera Microcystis, Anabaena and Planktothrix, among others. There are approximately 90 known isoforms of microcystins, varying in toxicity. The most toxic isoform is Microcystin-LR. Microcystins are hepatotoxins that inhibit protein phosphatases, damaging hepatocyte cytoskeletal structures, causing cells to shrink and blood to seep into liver structures. ${ }^{1}$
The Australian Drinking Water Guidelines (2004) and the Australian Guidelines for Managing Risk in Recreational Water (2008) provide water quality criteria to protect the public from contaminated drinking water and recreational exposure. To achieve this, a three-level alert system has been developed. Both guidelines acknowledge a paucity of epidemiological evidence on the relationship between cyanobacteria and human health. ${ }^{3,4}$

\section{Potential for future research}

The genes encoding biosynthesis of the major cyanobacterial toxins have been identified and characterised in the past 11 years. This has opened up possibilities to use advanced molecular biology techniques to gain a better understanding of environmental factors that influence the toxicity of cyanobacterial genera. Research is being conducted to identify how cyanobacterial cells sense their environment via the production of regulatory proteins. These proteins bind to DNA regions associated with toxin genes resulting in an increase or decrease in the transcription of genes and the amount of toxin biosynthetic enzymes within the cell. Outcomes of this research will make it possible to predict changes in toxicity of a bloom based on the chemistry of the water. ${ }^{5}$

\section{Penrith Lakes assessment}

The Penrith Lakes, located $60 \mathrm{~km}$ west of the Sydney CBD, are rehabilitated quarries forming a closed system from the nearby Nepean River. The Lakes offer various recreational activities at Penrith Whitewater Stadium and Sydney International Regatta Centre. The Penrith Lakes Development Corporation (PLDC) is responsible for managing and testing the water within the Lakes.

Public Health Units have a role in advising water managers about potential health effects of cyanobacteria-affected water. The Nepean Blue Mountains Public Health Unit (NBMPHU), together with the PLDC and staff from Whitewater Stadium and the Regatta Centre, has developed a public health response to cyanobacterial blooms at the Lakes which may impact on the health of recreational users. The NBMPHU, in consultation with the PLDC, has developed site-specific cyanobacteria and cyanotoxin guidelines for cylindrospermopsin and saxitoxins to protect recreational users of the Lakes. Both guidelines have been endorsed by the NSW State Algal Authority. 


\section{References}

1. Carmichael WW. Cyanobacteria secondary metabolites - the cyanotoxins. J Appl Bacteriol 1992; 72(6): 445-59. doi:10.1111/ j.1365-2672.1992.tb01858.x

2. Pilotto LS, Douglas RM, Burch DB, Cameron S, Beers M, Rouch GJ et al. Health effects of exposure to cyanobacteria (blue-green algae) during recreational water-related activities. Aust N Z J Public Health 1997; 21: 562-6. doi:10.1111/ j.1467-842X.1997.tb01755.x

3. National Health and Medical Research Council. Australian Drinking Water Guidelines. Canberra: Australian Government Natural Resource Management Ministerial Council; 2004.
4. National Health and Medical Research Council. Guidelines for Managing Risks in Recreational Water. Canberra: Australian Government Department of Health and Ageing; 2008.

5. Pearson LA, Moffitt MC, Ginn HP, Neilan BA. The molecular genetics and regulation of cyanobacterial peptide hepatotoxin biosynthesis. Crit Rev Toxicol 2008; 38(10): 847-56. doi:10.1080/10408440802291513

\section{Coming in the second half of $2014 \ldots$}

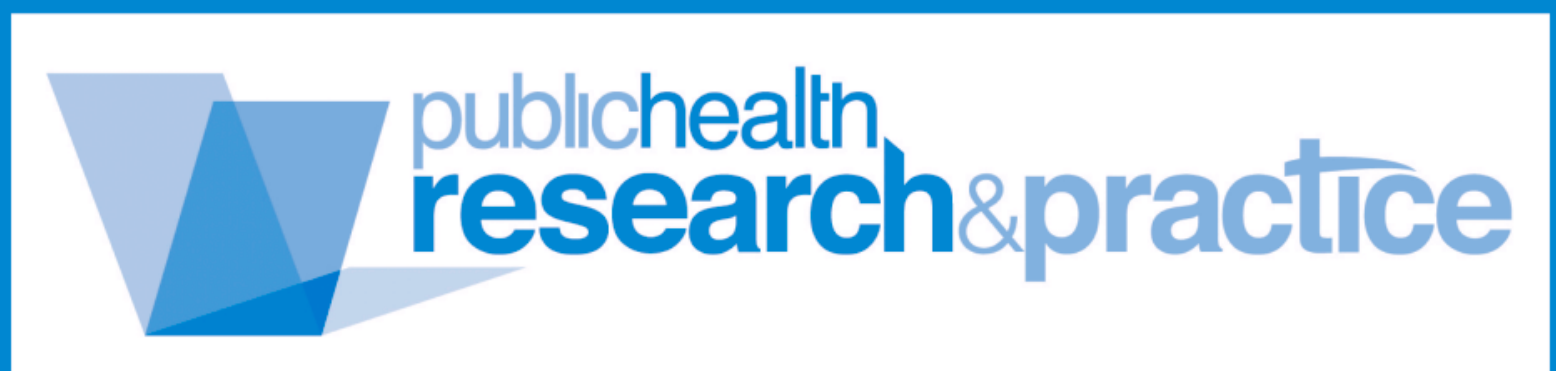

To subscribe visit http://bit.ly/journalsubscribe 